\title{
Identification and characterisation of common glow-worm RNA viruses
}

\author{
Lumi Viljakainen $^{1} \cdot$ Anna-Maria Borshagovski $^{1} \cdot$ Sami Saarenpää ${ }^{1} \cdot$ Arja Kaitala $^{1}$ Jaana Jurvansuu ${ }^{1}$ (I)
}

Received: 4 December 2019 / Accepted: 16 December 2019 / Published online: 3 January 2020

(c) The Author(s) 2019

\begin{abstract}
The common glow-worms (Lampyris noctiluca) are best known for emission of green light by their larvae and sexually active adult females. However, both their DNA and RNA viruses remain unknown. Glow-worms are virologically interesting, as they are non-social and do not feed as adults, and hence their viral transmission may be limited. We identified viral sequences from 11 different virus taxa by the RNA-sequencing of two Finnish populations of adult glow-worms. The viruses represent nine different virus families and have negative, positive, or double-stranded RNA genomes. We also found a complete retroviral genome. Similar viral sequences were found from the sequencing data of common eastern firefly of North America, a species belonging to the same family (Lampyridae) as that of the common glow-worm. On average, an individual glow-worm had seven different RNA virus types and most of them appeared to establish a stable infection since they were found from glow-worms during two consecutive years. Here we present the characterization of load, prevalence, and interactions for each virus. Most of the glow-worm RNA viruses seem to be transmitted vertically, which may reflect the biology of glow-worms as non-social capital breeders, i.e., they invest stored resources in reproduction.
\end{abstract}

Keywords Common glow-worm $\cdot$ RNA viruses $\cdot$ Rna-sequencing $\cdot$ Virus transmission

\section{Introduction}

The common glow-worm (Lampyris noctiluca) is a nocturnal beetle, whose larvae and sedentary females emit highly visible green light. Larva glow is a warning signal for distastefulness [1-3] and adult females produce green light to attract flying males $[4,5]$. Glow-worms are capital breeders: they feed only as larvae, rendering this stage critical for storing energy, and potentially, for acquiring commensal and pathogenic organisms. Larval development takes one to four years and adult lifespan is of few weeks [4]. Most adult females glow for only one or a few nights to attract males, which is followed by mating, and soon after, they lay their

Edited by Lorena Passarelli.

Electronic supplementary material The online version of this article (https://doi.org/10.1007/s11262-019-01724-5) contains supplementary material, which is available to authorized users.

Jaana Jurvansuu

jaana.jurvansuu@oulu.fi

1 Department of Ecology and Genetics, University of Oulu, Pentti Kaiteran katu 1, 90014 Oulu, Finland eggs and die. The common glow-worm is widely distributed across the northern hemisphere, from Portugal to China and from Spain to Finland $[4,6]$.

Glow-worm populations seem to be isolated from each other due to local differences in their emergence time and females' inability to fly. This lack of conspecific contact makes glow-worms epidemiologically interesting. Larvae are predators feeding mainly on slugs and snails, and at early stages the larvae may forage together [4]. Individuals from different populations have limited contact with each other, and likewise, individuals within one population meet perhaps only at birth, during larval stage, and mating [4, 7]. Thus, horizontal virus transmission, that is, transmission between individuals of the same generation, is presumably quite limited. So far the only viruses found in Lampyridae family, the two orthomyxo-like viruses found in the North American common eastern firefly (Photinus pyralis), were observed to be transmitted vertically, that is, from parent to offspring [8].

We identified viral sequences from two Finnish glowworm populations and studied their presence in different life stages and tissues in Finnish and English glow-worms. We identified 11 RNA viruses from adult glow-worms, four 
positive-stranded, three negative-stranded, three doublestranded, and one retrovirus. Most of the viruses formed stable infections as they were obtained from glow-worms collected in two different years. The glow-worm viruses are found in egg tissue as well as unfed larvae, which suggests that most of them may be transmitted vertically from parents to offspring.

\section{Material and methods}

\section{Glow-worms}

The data consists of several cohorts: (1) Adult female and male glow-worm samples used for RNA-sequencing were collected from two Finnish populations: Nine females and four males from Konnevesi (in the middle of Finland, N62 $37^{\prime}$, E26 $20^{\prime}$, collected in July and August 2017); and eight females and eight males from Hanko (southern Finland, $\mathrm{N} 59^{\circ} 53^{\prime}$, E23 ${ }^{\circ} 06^{\prime}$, collected in June and July 2017). (2) Adult female samples, used for qPCR analyses, were collected in June and July, 2018, from two populations, four females from Äänekoski (in the middle of Finland, N62 ${ }^{\circ}$ $36^{\prime}$, E25 $43^{\prime}$ ), and five females from Tvärminne Zoological Station (southern Finland, N59 $9^{\circ} 50^{\prime}$, E23 $14^{\prime}$ ). (3) Laboratory-reared larvae from different mothers were used for qPCR analyses. Mothers of three of these larvae were collected from southern Finland (Lohja, Öby, and Särkisalo) and mated in 2016, and three larvae with unknown relations were collected from England (Princes Risborough, $\left.\mathrm{N} 51^{\circ} 43^{\prime}, \mathrm{W} 0^{\circ} 50^{\prime}\right)$. These six larvae were reared and kept in the laboratory for two years and fed with organic cat food and terrestrial and aquatic snails collected from southern Finland. (4) Two-week-old larval offspring of two parental glow-worms (collected and mated in June 2018) were obtained from Tvärminne Zoological Station. The larvae $(N=12)$ hatched one month after egg-laying and were kept alive, unfed for 2 weeks. Online Resource 1 shows a map of sample collection sites. All the insects were stored in RNAlater until RNA extraction.

\section{RNA isolation, RNA-seq, and cDNA}

Female lanterns and male heads of samples from 2017 were individually dissected and used for RNA extraction, using RNeasy Micro Kit (Qiagen). The RNA samples were sent to BGI Tech Solutions for poly-A selected and strand-specific library preparation using Illumina TruSeq Stranded mRNA Library Prep Kit and RS-122-2101 kit. The libraries were sequenced with Illumina HiSeq4000 producing 100 bp pairedend reads. Samples from 2018 were isolated with Trizol (ThermoFisher). cDNA was prepared using $500 \mathrm{ng}$ total-RNA with
ReverAid H Minus First Strand cDNA synthesis kit (ThermoFisher), as per the manufacturer's protocol.

\section{Bioinformatics analysis}

The raw RNA-seq reads from the 2017 samples were trimmed for adapters and low-quality nucleotides $(\mathrm{Q}<20)$ and filtered for reads less than $36 \mathrm{nt}$ in length. The trimmed reads were pooled and assembled using Trinity v2.3.2 with in silico normalization [9]. Contigs over $1000 \mathrm{nt}$ were aligned to each other using CAP3 [10]. Contigs were pooled and searched using Blastx v2.3.0 [11] (an $e$-value $<10^{-10}$ and culling limit 1) against invertebrate virus protein sequences using NCBI virus protein RefSeq (downloaded in May, 2018). Contigs from individual data were translated to protein sequences with Transdecoder (github.com/TransDecoder), and only the longest of protein coding sequence over 160 aa was selected for search with Blastp against the invertebrate virus proteins. Virus positive contigs were pooled and aligned with each other with CAP3 and searched using Blastx, as above. Virus contigs were manually checked for complete or nearly complete viral genomes using NCBI ORFfinder (www.ncbi.nlm.nih.gov/ orffinder/). All the identified viral sequences were seeded into NOVOplasty [12] with the original RNA-sequencing data to make sure that the viral sequences were as complete as possible. The data are deposited into at NCBI (PRJNA577041). Coverage and alignment of the reads to the virus sequences were studied with IGV [13] so that at least two reads were covering the reference sequence at any site. Remapping of reads from each glow-worm separately to virus sequences was done with BWA [14].

NCBI Blastp (nr) was used to identify possible domains and identical protein sequences: identity describes, which percent of characters in the query sequence is identical with the target sequence and coverage describes how much of the query sequence is covered by the target sequence. HHpred [15] was used to search for remote homologous proteins based on protein structure prediction. RNAfold (rna.tbi. univie.ac.at/cgi-bin/RNAWebSuite/RNAfold.cgi) was used to predict stable genomic RNA structures.

Similar virus sequences to glow-worm viruses were searched with Blastx from other insects (taxid:6960) from NCBI's transcriptome shotgun assembly sequence database (TSA). We set Blastx bit score, which takes into account the alignment length, mismatches and gaps, above 200 for positive hits.

\section{Phylogenies}

Phylogenies were reconstructed from the RdRP amino acid sequences of each virus and 19 most similar hits in Blastp, RSA TSA hits (Table 2), and virus sequences from Shi 
et al. [16]. Sequences were aligned using E-INS-I method in MAFFT v7.313 [17] and prior to phylogenetic analysis the alignments were trimmed using trimAl v1.2 [18]. Amino acid substitution model was selected using ProtTest 3 [19] and phylogeny reconstruction was performed using PhyML v.3.0 [20]. Phylogenies were processed with iTOL [21].

\section{Quantitative-PCR (qPCR)}

qPCR was performed with virus-specific primers (Online Resource 2) using EvaGreen (Solis BioDyne) kit, as per manufacturers' protocol. Standards for qPCR were created with virus-specific primers using Phusion enzyme (ThermoFisher). The PCR products were isolated with GeneJET gel extraction kit (ThermoFisher). Only the results with over 10 viral sequences were analyzed further.

\section{Statistical analysis}

All statistical analyses were performed in R v3.5.0 (www.Rproject.orf/). Pairwise analysis of virus reads was done by Spearman's correlation using multiple testing p-value correction.

\section{Results}

\section{Virus identification}

We identified 11 RNA viruses by whole-transcriptome sequencing of 29 adult glow-worms. The samples were from two Finnish populations collected in 2017, four males (heads) and eight females (lanterns) from Konnevesi Research Station and eight males (heads) and nine females (lanterns) from Hanko (Online Resource 1). The tissues were chosen because they are important in sexual signaling. Viral sequences were assembled from pooled sample with the Trinity assembler (Table 1) and virus contigs were identified by protein similarity search against National Center for Biotechnology Information (NCBI) virus protein database. The virus sequences were deposited into NCBI GenBank database (Table 2). The viruses were named according to their genomic organization (Fig. 1) and phylogenetic relationship to known insect viruses (Online Resources 5-12): Lampyris noctiluca flavivirus 1, Lampyris noctiluca iflavirus 1, Lampyris noctiluca iflavirus 2, Lampyris noctiluca macula-like virus 1, Lampyris noctiluca bunya-like virus 1, Lampyris noctiluca rhabdo-like virus 1, Lampyris noctiluca chuvirus-like virus 1, Lampyris noctiluca partiti-like virus 1, Lampyris noctiluca partiti-like virus 2, Lampyris noctiluca totivirus-like virus 1 , and Lampyris noctiluca errantivirus 1. The sequence data were strand-specific and allowed us to separate the negative-strand replicative intermediates of positive-strand viruses and positive-strand transcripts of negative-strand viruses (Online Resource 3). The strand-specific data indicated that all identified positive-strand RNA viruses were replicating in the glow-worms. However, as the production of the sequencing library involved poly-A enrichment that biases the ratios of the virus transcripts, the strand-specific data were not analyzed further.

We analyzed also virus sequence variation between the samples (Online Resource 3). However, only fraction of the glow-worms had complete virus sequences without

Table 1 Virus sequence identification from the pooled glow-worm RNA-sequencing data

\begin{tabular}{|c|c|c|c|c|c|c|c|}
\hline Virus & Full virus name & Family & Genome type & Length (nt) & Reads & Coverage $^{\mathrm{a}}$ & $\mathrm{RPKM}^{\mathrm{b}}$ \\
\hline LnoFV1 & Lampyris noctiluca flavivirus 1 & Flaviviridae & ssRNA + & 18,912 & 40,858 & 216.04 & 1.16 \\
\hline LnoIV1 & Lampyris noctiluca iflavirus 1 & Iflaviridae & ssRNA+ & 10,286 & 383,062 & 3724.11 & 19.91 \\
\hline LnoIV2 & Lampyris noctiluca iflavirus 2 & Iflaviridae & ssRNA+ & 10,369 & $1,316,524$ & $12,696.73$ & 67.9 \\
\hline LnoMLV1 & Lampyris noctiluca macula-like virus 1 & Tymoviridae & ssRNA+ & 6733 & $36,646,669$ & $544,284.41$ & 2910.35 \\
\hline LnoBLV1 & Lampyris noctiluca bunya-like virus 1 & Bunyaviridae & ssRNA - & 6774 & 1447 & 21.36 & 0.11 \\
\hline \multirow[t]{3}{*}{ LnoRLV1 } & \multirow[t]{3}{*}{ Lampyris noctiluca rhabdo-like virus 1} & \multirow[t]{3}{*}{ Rhabdoviridae } & \multirow[t]{3}{*}{ ssRNA - } & 6183 & 1003 & 16.22 & 0.09 \\
\hline & & & & 2571 & 3408 & 132.56 & 0.71 \\
\hline & & & & 1743 & 1794 & 102.93 & 0.55 \\
\hline \multirow[t]{2}{*}{ LnoCLV1 } & \multirow[t]{2}{*}{ Lampyris noctiluca chuvirus-like virus 1} & \multirow[t]{2}{*}{ Chuviridae } & \multirow[t]{2}{*}{ ssRNA - } & 6829 & 3727 & 54.58 & 0.29 \\
\hline & & & & 4489 & 27,337 & 608.98 & 3.26 \\
\hline LnoPLV1 & Lampyris noctiluca partiti-like virus 1 & Partitiviridae & dsRNA & 1462 & 71 & 4.86 & 0.03 \\
\hline LnoPLV2 & Lampyris noctiluca partiti-like virus 2 & Partitiviridae & dsRNA & 1461 & 11,206 & 767.01 & 4.1 \\
\hline LnoTLV1 & Lampyris noctiluca totivirus-like virus 1 & Totiviridae & dsRNA & 4761 & 468 & 9.83 & 0.05 \\
\hline LnoErV1 & Lampyris noctiluca errantivirus 1 & Metaviridae & Retrovirus & 6931 & 1566 & 22.6 & 0.00012 \\
\hline
\end{tabular}

${ }^{a}$ All virus-specific bases divided by virus length

${ }^{\mathrm{b}}$ Reads Per Kilobase of transcript per Million mapped reads 
Table 2 Glow-worm viruses identified in this study and existence of similar viruses in other insects

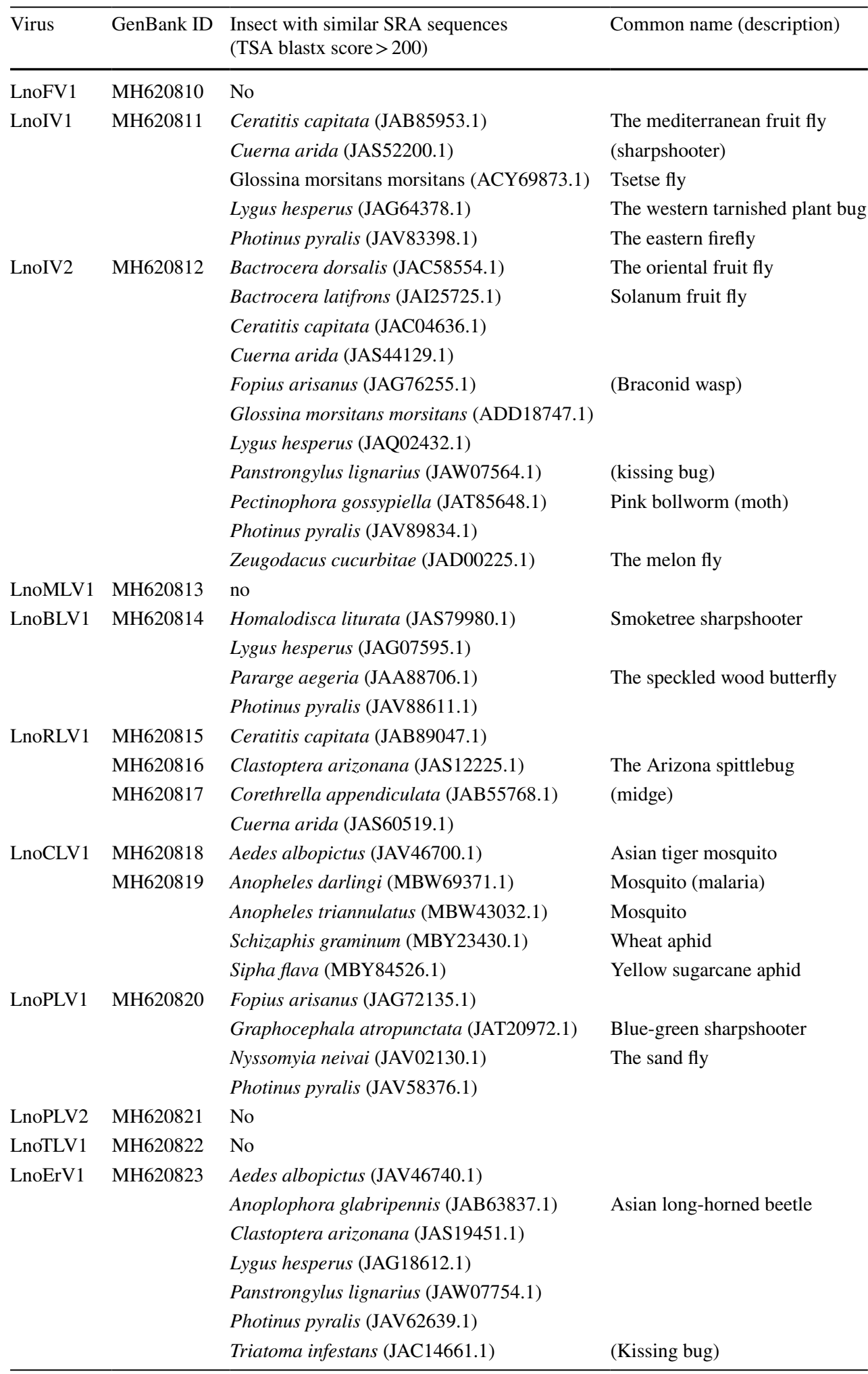

RSA NBCI's Sequence Read Archive, TSA NCBI's transcriptome shotgun assembly sequence database, in green are shown virus RdRP sequences that are present in virus phylogenies gaps and thus the analysis produced only descriptive information. When considering only southern population females that had at least two complete virus sequences per group, highest frequency of variable sites were with iflaviruses (LnoIV1: 0.0097 variable sites/genome size/sample number and LnoIV2: 0.0152), and lowest with flavivirus 


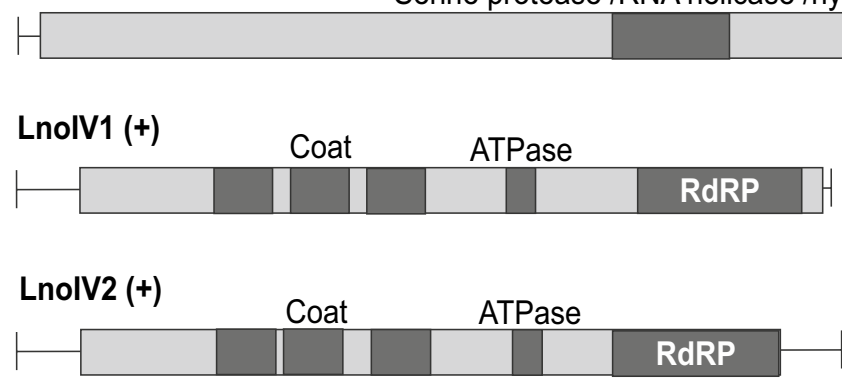

\section{LnoMLV1 (+)}

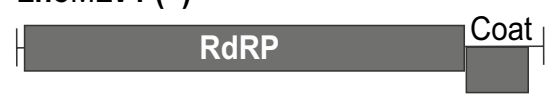

LnoBLV1 (-)

\section{RdRP}

\section{LnoRLV1 (-)}

\section{Coat}

\section{ENV}

\section{RdRP}

\section{LnoCLV1 (-)}

\section{ENV Coat}

RdRP

\section{LnoPLV1 (ds)}

\section{RdRP}

\section{LnoPLV2 (ds)}

\section{RdRP}

LnoTLV1 (ds)

\section{Coat}

\section{RdRP}

LnoErV1 (rt)

\section{Gag}

\section{RT}

Fig. 1 Genome organization of the glow-worm viruses: The virus genome type is indicated in parenthesis, after virus name: positive $(+)$, negative $(-)$, double-stranded (ds), or retrovirus (rt). Line denotes virus sequence and boxes open reading frames (ORFs). Dark gray boxes represent domains identified by HHpred or Blastp. The size in nucleotides is indicated for the largest virus and the sizes of the other viruses are in scale to that. LnoMLV1 has two ORFs in different reading frames presented by the two ORF boxes aligned above and below the sequence line. RdRP RNA-dependent RNA polymerase, Gag capsid, ENV envelope, and $R T$ reverse transcriptase 
LnoFV1 (0.00097) and partitivirus LnoPV1 (0.0010). Frequency of variable sites for partitivirus LnoPLV2 was 0.0016 variable sites/genome size/sample number.

\section{Lampyris noctiluca flavivirus 1}

Flaviviruses are positive-strand RNA viruses and include notorious arboviruses with mosquito (Dengue, Zika, Yellow Fever, West Nile, Japanese encephalitis) and tick vectors (tick-borne encephalitis virus). L. noctiluca flavivirus 1 (LnoFV1) is 18,917 nt long and encodes a 6152 aa polyprotein. Blastp search results indicated protein sequence similarity to the putative polyprotein of Drosophila flavivirus, Takaungu virus (19\% coverage with 59\% identity, NCBI taxonomy ID $=1,807,800$ ). HHpred found sites in the LnoFV1 sequence similar to Serine protease NS3/RNA helicase/ hydrolase of classical swine fever virus $(e$-value $=3.6 \mathrm{e}-$ 25, PDB ID $=5 \mathrm{WX} 1 \_\mathrm{A}$ ) and methyltransferase and RNAdependent RNA polymerase (RdRP) of Japanese encephalitis virus ( $e$-value 2e-34, protein data base id: 4K6M_A). Both swine fever virus and Japanese encephalitis virus are flaviviruses. On the basis of the phylogenetic analysis, LnoFV1 was most similar to Drosophila flavi-like viruses, Takaungu virus and Hermitage virus $(1,807,799)$ (Online Resource 5) [22]. RNAfold (rna.tbi.univie.ac.at) was used to predict secondary structures at the $5^{\prime}$ and $3^{\prime}$ untranslated regions and LnoFV1 was found to have highly structured 3' UTR typical for flaviviruses [23].

\section{Lampyris noctiluca iflavirus 1 and 2}

Iflaviruses are insect-infecting positive-strand RNA viruses coding for a single polyprotein. Lampyris noctiluca iflavirus 1 (LnoIV1) is 10,339 nt long and codes for a polyprotein of 3134 aa. Blastp indicates polyprotein similarity (47\% coverage and $28 \%$ identity) to a hypothetical protein of Hubei picorna-like virus $31(1,923,111)$ from odonata mix [16]. According to HHpred, the polyprotein had sites similar to human rhinovirus 16 coat protein $(e$-value $=1.6 \mathrm{e}$ 23, 1AYM_2), coat protein of iflavirus Deformed wing virus $\left(e\right.$-value $\left.=2 \mathrm{e}-42,5 \mathrm{MV} 5 \_\mathrm{C}\right)$, capsid protein of iflavirus Slow bee paralysis virus ( $e$-value $\left.=1.9 \mathrm{e}-17,5 \mathrm{~J} 98 \_\mathrm{A}\right)$, ATPase of enterovirus 2C ( $e$-value $=4.6 \mathrm{e}-13$ 5GQ1_C), and RdRP of human polio virus 1 ( $e$-value $\left.=9.9 \mathrm{e}-65,2 \mathrm{IJD} \_1\right)$. All the HHpred identified viruses belonged to the Picornavirales order. Based on the phylogenetic analysis LnoIV1 was most closely related to unclassified bat Rolda virus $(1,911,103)$ (Online Resource 6). Stable RNA structures, which could function as an internal ribosomal entry site (IRES), were identified by RNAfold on the first 729 nucleotides.

Lampyris noctiluca iflavirus 2 (LnoIV2) is 10,428 nt long and codes a polyprotein of 3132 aa. Blastp search shows polyprotein similarity $(73 \%$ coverage and $26 \%$ identity) to unclassified bat virus polyprotein of Rolda virus $(1,911,103)$. According to HHpred, the polyprotein had sites similar to the capsid proteins of Slow bee paralysis virus $\left(e\right.$-value $=1.9 \mathrm{E}-26,5 \mathrm{~J} 98 \_\mathrm{B}$ and $e$-value $=1.7 \mathrm{e}-47$ 5J98_C $)$ and Deformed wing virus ( $e$-value $\left.=1.6 \mathrm{E}-21,5 \mathrm{MV} 5 \_\mathrm{A}\right)$, ATPase of enterovirus $2 \mathrm{C}$ ( $e$-value $\left.=1.7 \mathrm{E}-10,5 \mathrm{GQ} 1 \_\mathrm{B}\right)$, and $\mathrm{RdRP}$ of human poliovirus 1 ( $e$-value $\left.=1.2 \mathrm{e}-62,22 \mathrm{IJD} \_2\right)$. All HHpred identified viruses belong to the Picornavirales order. According to phylogenetic analysis, LnoIV2 was most similar to Hubei picorna-like virus $31(1,923,111)$ from odonata mix [16] (Online Resource 6). Stable RNA structures, which could function as IRES, were identified on the first 1002 nucleotide. Polyprotein similarity between $L$. noctiluca iflavirus 1 and 2 is $29.5 \%$ with $33 \%$ coverage. Thus, the sequence identity at the amino acid level between the capsid proteins is less than $90 \%$ and the viruses represent separate new species according to the International Committee on Taxonomy of Viruses (ICTV).

\section{Lampyris noctiluca macula-like virus 1}

Tymoviridae are positive-strand RNA viruses without an envelope. Tymoviruses infect mainly plants but they have also been found in insects, such as, bees (NCBI txid:1,682,186) $[24,25]$, silkworms $(288,456$ and $2,065,033)$ [26], mites $(1,682,187$ and $1,005,993)$ [25], and mosquitoes $(1,236,047)$ [27].

Lampyris noctiluca macula-like virus 1 (LnoMLV1) is $6744 \mathrm{nt}$ long with two open reading frames (ORFs). The longer ORF codes for a protein of 1920 aa, which was similar to an RdRP and a hypothetical protein of Bombyx mori Macula-like virus (txid:288,456, 84\% coverage with 56\% identity) according to Blastp search. The best hit by HHpred was a replicase of Tomato mosaic virus $(e$-value $=3 \mathrm{e}-24$, pdb:3VKW_A), and several shorter hits to viruses of the Tymoviridae family. Shorter ORF, coding for a protein of 231 aa, was similar (98\% coverage and $45 \%$ identity) to a coat protein of Bee Macula-Like virus 2 (2,094,260), according to Blastp search. HHpred showed that the ORF was similar to plant tymovirus desmodium yellow mottle virus capsid protein $(e$-value $=6.8 \mathrm{e}-59,1 \mathrm{DDL} C \mathrm{C})$. Species demarcation criteria for Maculavirus genus is by ICTV less than $90 \%$ identity in capsid protein. Based on phylogenetic analysis, LnoMLV1 was most similar to Bee Macula-Like virus $2(2,094,260)$ (Online Resource 7$)$.

\section{Lampyris noctiluca bunya-like virus 1}

Bunyaviruses have tripartite negative-strand RNA genomes coding for RdRP, nucleoprotein, and envelope proteins. Only the $6774 \mathrm{nt}$ RdRP genome was found for the Lampyris noctiluca bunya-like virus 1 (LnoBLV1). The 2182 aa long protein was most similar to Hubei insect virus 1 RdRP 
$(1,922,897)$ and several bat bunyaviruses $(98 \%$ coverage and 39\% identity, AOY18798.1-AOY18800.1) according to Blastp search. HHpred showed that the protein was similar to RNA polymerase L (5AMR_A) of bunyavirus "la Crosse". Phylogenetic analysis placed LnoBLV1 closest to hypothetical protein of Smoketree sharpshooter (Table 2), Hubei insect virus $1(1,922,897)$ from arthropod mix (Online Resource 8) [16].

\section{Lampyris noctiluca rhabdo-like virus 1}

Rhabdoviruses are monopartite negative-strand RNA viruses. $L$. noctiluca rhabdo-like virus 1 (LnoRLV1) was found in three parts. The longest transcript of $6218 \mathrm{nt}$ codes for a protein of 1924 aa, which according to Blastp search, is similar to Hubei rhabdo-like virus $3(1,923,187)$ RdRP from Coleoptera mix (99\% coverage and 34\% identity). According to HHpred, the protein was similar to vesicular stomatitis virus L polymerase $\left(e\right.$-value $\left.=3.8 \mathrm{e}-190,5 \mathrm{~A} 22 \_\mathrm{A}\right)$. The second transcript of $2571 \mathrm{nt}$ encodes a protein of 603 aa. Blastp search indicated the similarity of the protein to Hubei rhabdo-like virus 3 hypothetical protein 1 ( $80 \%$ coverage and $23 \%$ identity), and HHpred analysis showed that the protein was somewhat similar to fusion glycoprotein of Hendra virus $\left(e\right.$-value $\left.=0.00002,5 \mathrm{EJB} \_\mathrm{C}\right)$, which suggests that the protein codes for an envelope. The smallest transcript of $1743 \mathrm{nt}$ codes for a protein of 426 aa, which Blastp search found most similar to putative glycoprotein of Hubei rhabdolike virus 3 (39\% coverage and 28\% identity), and HHpred showed a weak similarity to $\mathrm{p} 40$ nucleoprotein of Borna disease virus ( $e$-value $\left.=23,1 \mathrm{~N} 93 \_\mathrm{X}\right)$ from the Mononegavirales order, to which the rhabdoviruses belong. Thus, the smallest transcript most probably codes for a capsid protein. Based on the phylogenetic analysis, LnoRLV1was most similar to Hubei rhabdo-like virus $3(1,923,187)$ isolated from a beetle mix [16] (Online Resource 9).

\section{Lampyris noctiluca chuvirus-like virus 1}

Chuviridae is a negative-stranded RNA virus family within the order Mononegavirales, with variable genome structures i.e. segmented, non-segmented, and circular [28]. LnoCLV1 genome had two segments, the larger genome of $6829 \mathrm{nt}$ and encodes a protein of 2206 aa and the smaller segment that was $4489 \mathrm{nt}$ long, with three ORFs coding for 693, 407, and 115 aa long proteins. According to Blastp search, the protein from the larger genome segment was similar to RdRP of Hubei chuvirus-like virus 3 (100\% coverage and $43 \%$ identity, 1,922,858), and HHpred showed similarity to vesicular stomatitis virus $\mathrm{L}$ polymerase $\left(e\right.$-value $\left.=5.2 \mathrm{e}-185,5 \mathrm{~A} 22 \_\mathrm{A}\right)$. According to Blastp search, the 693 amino acids protein was similar to putative glycoprotein of Hubei chuvirus-like virus 3 (91\% coverage and 49\% identity) and HHpred showed similarity to the envelope glycoprotein of human herpesvirus $1(e$-value $=1.6 \mathrm{e}-27)$, which suggests that the ORF codes for an envelope protein. The 407 aa protein was similar to a hypothetical protein of Hubei chuvirus-like virus 3 (Blastp: 95\% coverage and 37\% identity), and HHpred showed protein structural similarity to 40 nucleoprotein of Borna disease virus $\left(e\right.$-value $\left.=2.6,1 \mathrm{~N} 93 \_\mathrm{X}\right)$ suggesting that the ORF may code for a coat protein. For the shortest protein of 115 aa, neither Blastp nor HHpred found any significantly similar proteins. According to phylogenetic analysis, LnoCLV1 was most similar to Hubei chuvirus-like virus $3(1,922,858)$ (Online Resource 9), which has been isolated from Odonata mix and has a monopartite genome [16].

\section{Lampyris noctiluca partiti-like virus 1 and 2}

Partitiviruses are small bipartite double-stranded RNA viruses coding for RdRP and capsid proteins. We could only find the RdRP coding segment for two partitivirus-like viruses identified from the glow-worms. Lampyris noctiluca partiti-like virus 1 (LnoPLV1) genome was $1462 \mathrm{nt}$ long and codes for a protein of 377 aa. According to Blastp search, the protein is similar to RdRP of Hubei partiti-like virus 31 $(1,923,038,93 \%$ coverage and $72 \%$ identity). HHpred showed that the protein sequence was similar to RdRP of negativestrand RNA virus, Thosea asigna virus $(e$-value $=1.5 \mathrm{e}-36$, 5CX6_B). In phylogenetic analysis LnoPLV1 was closest to Hubei partiti-like virus 31 (Online Resource 10) isolated from spider mix. Only the RdRP genome segment was identified in the Hubei partiti-like virus 31 [16].

Lampyris noctiluca partiti-like virus 2 (LnoPLV2) genome segment was $1461 \mathrm{nt}$ long and encoded a 436 aa protein. Blastp search showed similarity to RdRP of Hubei partiti-like virus 51 (90\% coverage and $42 \%$ identity, 1,923,060), which was closest in the phylogenetic analysis also (Online Resource 10). Hubei partiti-like virus 51 was identified from Chinese land snail mix, and only RdRP segment was found, as observed in LnoPLV2, HHpred showed that LnoPLV2 RdRP is most similar to Mengo virus RdRP (8.6e-37, 4NYZ_A). Mengo virus belongs to the Picornaviridae family. LnoPLV1 and LnoPLV2 are separate species as their had only $28.6 \%$ identity over RdRP residues ( $57.6 \%$ coverage) and were only distantly related by phylogenetic analysis (Online Resource 10).

\section{Lampyris noctiluca totivirus-like virus 1}

Totiviruses are double-stranded RNA viruses without an envelope. L. noctiluca totivirus-like virus 1 (LnoTLV1) genome is $4761 \mathrm{nt}$ long and contains two ORFs coding for proteins of 834 and 693 aa. As seen in Blastp search, the longer ORF was similar to hypothetical protein 3 of Hubei toti-like virus 16 (90\% coverage with $24 \%$ identity, 1,923,304). HHpred found the longer ORF similar to 


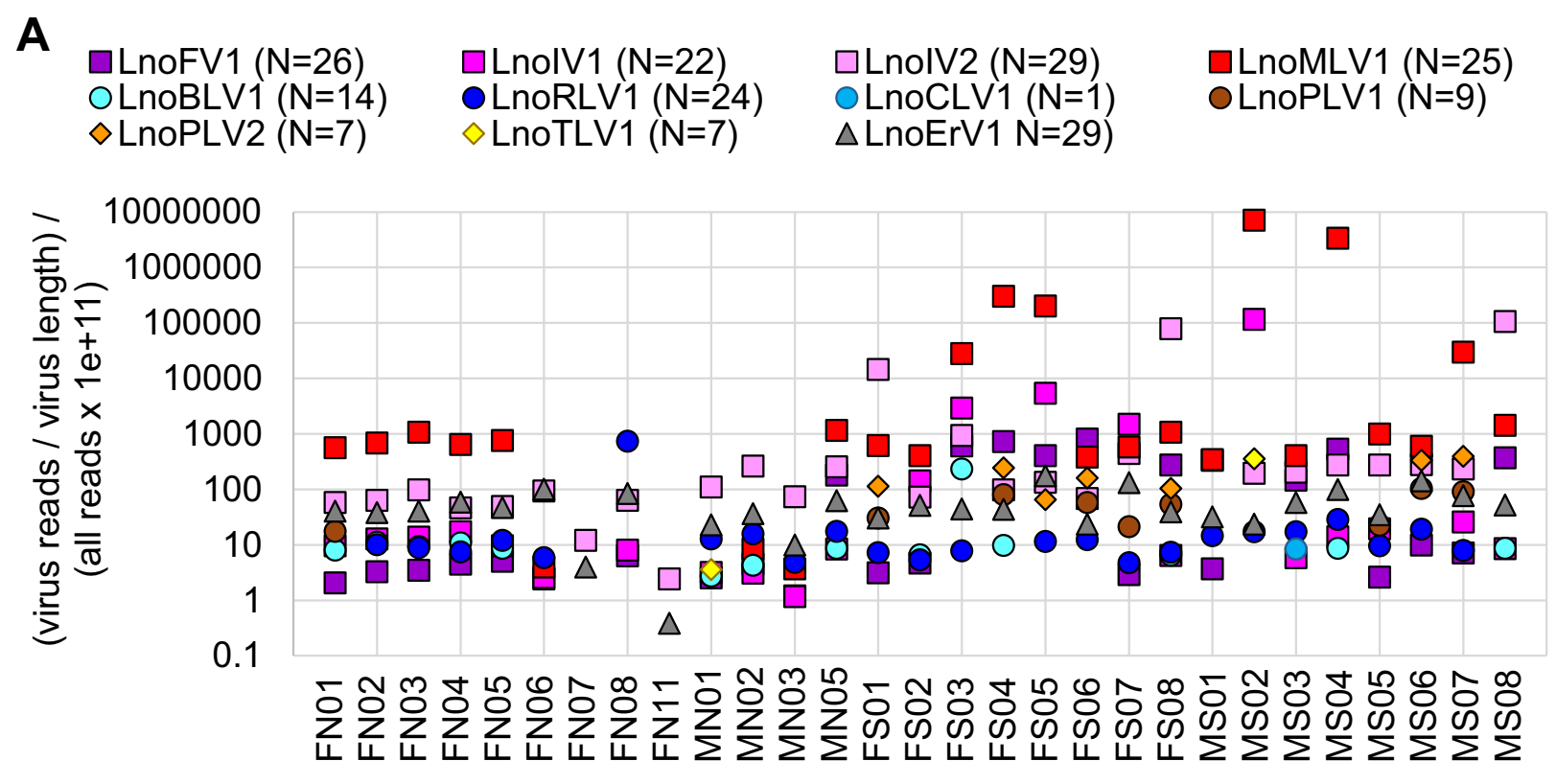

B

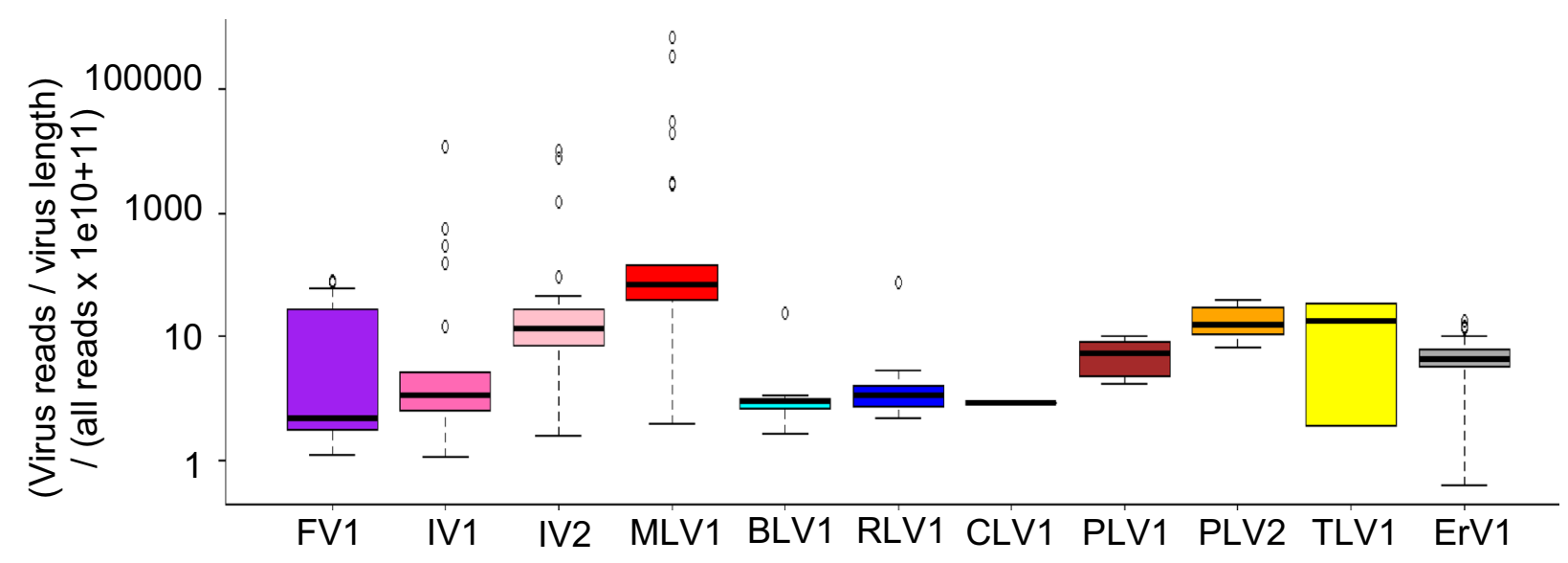

C

D.
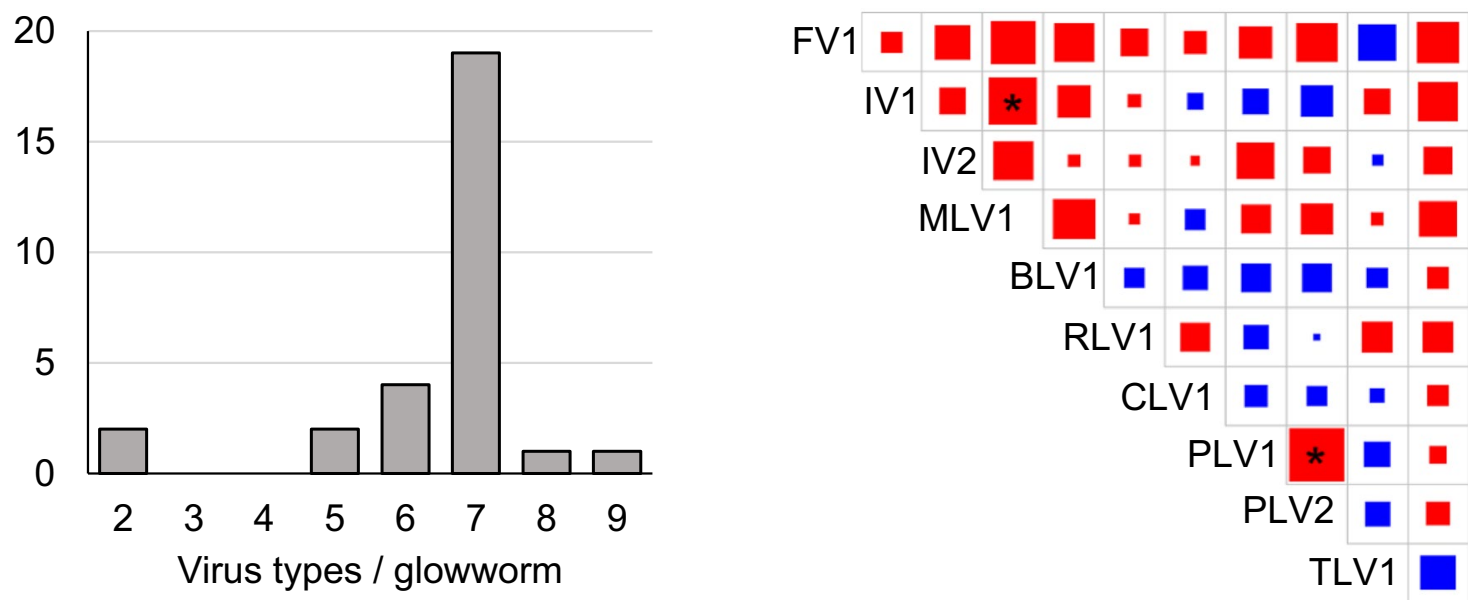

ErV1 
४Fig. 2 Glow-worm RNA virus loads, prevalence, and interactions: a individual standardized read amounts for the 11 viruses were plotted for each glow-worm $(N=29)$. Virus color code is given above the scatter plot. Females and males from the northern population (Konnevesi) are marked $\mathrm{FN}$ and $\mathrm{MN}$, and females and males from the southern population (Hanko) are marked FS and MS, respectively. b Each glow-worm virus has its typical load levels. Box plots show variation of virus-specific reads in the glow-worms. Black line represents median value, values inside the box cover first and third quartile (interquartile) range, the whisker show values up to 1.5 times the interquartile range, and gray circles are individual values beyond the whisker range (outliers). c Glow-worms infected, on average, by seven different virus types. d Possible virus interactions were analyzed by pairwise comparison of virus read amounts with Spearman's correlation coefficient. Positive correlation is indicated by red, negative correlation by blue, and the magnitude of the adjusted p-values is indicated by the size of the colored square. The two statistically significant interactions are shown by asterisk: LnoIV1 and LnoMLV1, and LnoPLV1 and LnoPLV2 virus loads correlated positively with each other

RdRP of foot-and-mouth disease virus ( $e$-value $=3.6 \mathrm{e}-24$, 4WYW_A). According to Blastp search, the shorter ORF was similar to hypothetical protein 2 of Hubei toti-like virus 16 (99\% coverage and $31 \%$ identity), whereas HHPred found no similar protein sequences. Hubei toti-like virus 16 is isolated form spiders [16]. According to phylogenetic analysis, LnoTLV1 was most similar to Hubei toti-like virus 16 and Beihai sea slater virus 3, isolated from wharf roach $(1,922,659)$ (Online Resource 11).

\section{Lampyris noctiluca errantivirus 1}

Errantiviruses are endogenous retroviruses of insects. $L$. noctiluca errantivirus 1 (LnoELV1) genome is $6948 \mathrm{nt}$ long, with three ORFs in two reading frames and long-terminal repeats of 90 nucleotides. The largest ORF of 1096 aa is similar to uncharacterised protein of psyllid Diaphorina citri $(83 \%$ coverage and $66 \%$ identity, 121,845$)$ and ORF $\mathrm{B}$ of errantivirus Trichoplusia ni TED virus ( $81 \%$ coverage and $66 \%$ identity, 2,083,181) according to Blastp search. HHpred identified two sites similar to reverse transcriptase/ ribonuclease $\mathrm{H}$ p80 of moloney murine leukemia virus ( $e$-value $\left.=2.5 \mathrm{e}-56,4 \mathrm{MH} 8 \_\mathrm{A}\right)$ and to integrase of human spumaretrovirus $(e$-value $=1.6 \mathrm{e}-33,3 \mathrm{OYM}$-B $)$. The 508 aa protein sequence was similar to several predicted insect proteins (such as Tribolium castaneum: XP_015840241.1, Halyomorpha halys: XP_024219554.1, and Papilio machaon: XP_014361342.1) and envelope protein of Drosophila melanogaster ( $79 \%$ coverage and $27 \%$ identity, CAA04048.1), according to Blastp search. HHpred found protein similarity to fusion protein of newcastle disease virus $\left(e\right.$-value $\left.=0.0098,1 \mathrm{G} 5 \mathrm{G} \_\mathrm{C}\right)$. Blastp search found the shortest ORF of 317 aa to be similar to ORF A of Trichoplusia ni TED virus (70\% coverage and $33 \%$ identity). According to ICTV, species of errantiviruses have generally less than
$50 \%$ identity in their Gag protein. HHpred showed that the protein was similar to gag protein of rous sarcoma virus $\left(e\right.$-value $\left.=5.6 \mathrm{e}-13,5 \mathrm{~A} 9 \mathrm{E} \_\mathrm{B}\right)$. In phylogenetic analysis, LnoErV1 was found to be similar to uncharacterized proteins from several insects, such as, kissing bug, the old world swallowtail butterfly, fruit fly, louse, termite, ant, and silkworm, and transposons from the cabbage looper moth and red flour beetle, indicating that these insects have similar endogenous retroviruses (Online Resource 11).

\section{Glow-worm viruses in other insects}

We used NCBI's transcriptome shotgun assembly sequence database (TSA) to search for similar virus sequences in other insects. We set Blastx bit score, which takes into account the alignment length, mismatches and gaps, above 200 for positive hits. We found no similar viruses from insect transcriptomes for LnoFV1, LnoPLV2, or LnoTLV1 (Table 1). However, for the other viruses, we found similar sequences from several insect hosts, ranging from fruit flies and mosquitoes to bugs and sharpshooters (Table 1 and Online Resource 5-12). Interestingly, we found that a firefly (Photinus pyralis) shared five similar virus sequences (LnoIV1, LnoIV2, LnoBLV1, LnoPLV1, and LnoErV1) with glow-worms. The western tarnished plant bug (Lygus hesperus) shared four similar virus sequences (LnoIV1, LnoIV2, LnoBLV1, and LnoErV1), and the mediterranean fruit fly (Ceratitis capitata) and sharpshooter (Cuerna arida) shared three similar viruses (LnoIV1, LnoIV2, and LnoRLV1). All the insect hosts that had LnoIV1-like virus sequences also had LnoIV2-like virus.

\section{The glow-worm virus loads, prevalence, and interactions}

Viral RNA read amounts for samples collected in 2017 were analyzed for each glow-worm individually. Before the analysis, we removed poly-A-tails from the virus sequences. Only reads with a properly paired mate read mapping to the virus sequence were analyzed and the results were standardized by virus length and all clean reads of the sample (Fig. 2a). The most common viruses were LnoIV2 and LnoErV1, which were found in all samples. A high prevalence of LnoErV1 is expected as it is probably integrated into the glow-worm genome. The least common virus, found only in one sample, was LnoCLV1. The two Finnish glow-worm populations, southern Hanko and northern Konnevesi, had significantly different amounts of LnoFV1 (two-tailed student's $t$ test: $t=-3.14, p$-value $=0.0068$ for females, not significant in males), LnoPLV1 $(t=-2.73, p$-value $=0.015$ for females, not significant in males), and LnoPLV2 ( $t=-2.94, p$-value 0.01 for females, not significant in males). LnoFV1 load levels were higher in Hanko than those in Konnevesi population 
A

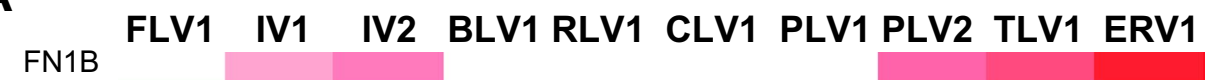

FN1E

FN1H

FN2B

FN2E

$\mathrm{FN} 2 \mathrm{H}$

FN3B

FN3E

$\mathrm{FN} 3 \mathrm{H}$

FN4B

FN4E

FN4H

FS1B

FS1E

$\mathrm{FS} 1 \mathrm{H}$

FS2B

FS2E

$\mathrm{FS} 2 \mathrm{H}$

FS3B

FS3E

$\mathrm{FS} 3 \mathrm{H}$

FS4B

FS4E

$\mathrm{FS} 4 \mathrm{H}$

FS5B

FS5E

$\mathrm{FS} 5 \mathrm{H}$

LF1B

LF1H

LF2H

LF3B

LF3H

LE1B

LE1H

LE2B

LE2H

LE3B

LE3H

2wL1

2wL2

FLV1 IV1 IV2 BLV1 RLV1 CLV1 PLV1 PLV2 TLV1 ERV1
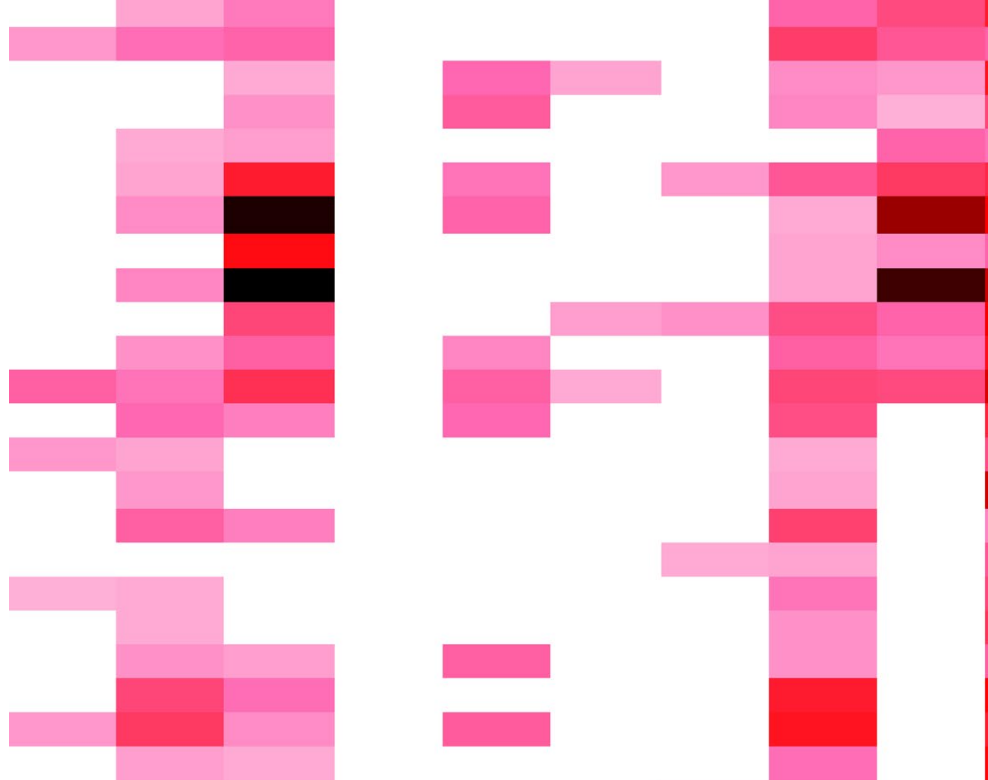

(1)

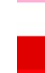
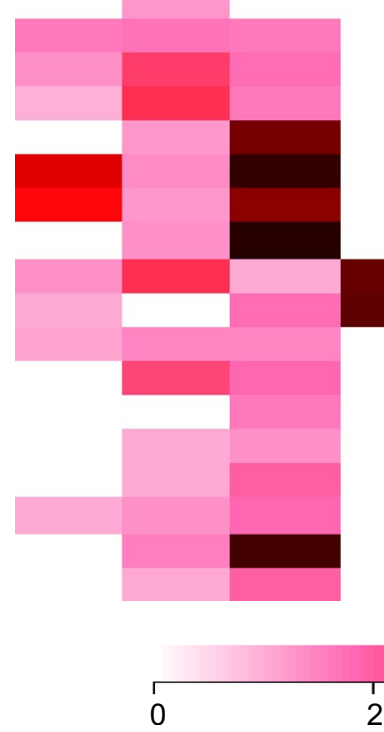

2

4

6

B

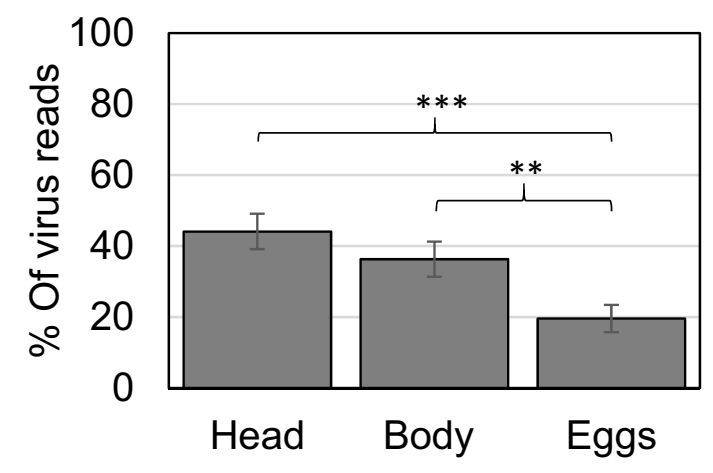

c.

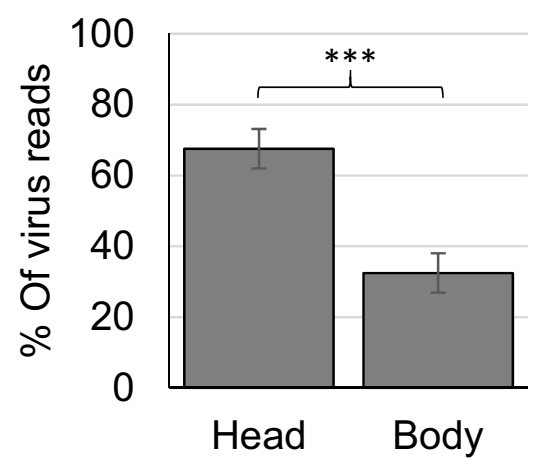


4Fig. 3 Virus loads in 2018 glow-worm samples: a the glow-worm RNA virus levels were studied by qPCR from head $(\mathrm{H})$, body (B), and eggs (E) of nine Finnish glow-worm females from two populations (FN: Äänekoski and FS: Tvärminne) and from heads (H) and bodies (B) of three laboratory-reared larvae from Finland (LF) and three from England (LE). Additionally, 12 unfed 2-week-old larvae split into two pools ( 2 wL1 and 2 wL2) were also studied. Virus loads in 10-based logarithmic scale shown in a heat map from white (no virus) to dark red (loads over 1,000,000 virus sequences per sample). The bar blots show the virus distribution between the different body parts in b females $(N=7)$ and $\mathbf{c}$ Larvae $(N=6)$. The sum of virus reads in all of the body parts is $100 \%$. Variation is shown by standard error and significant differences between groups by asterisk $(* * *=p$-value $<0.001$, and $* *=p$-value $<0.01)$

and partiti-like viruses were almost exclusively found in the Hanko population.

Viral load variation was analyzed for each virus separately (Fig. 2b). The positive-strand RNA virus loads varied somewhat more than the other RNA viruses; for example, positive-strand RNA viruses had a larger interquartile value range and more outlier values. Especially, LnoMLV1 had five outlier values, of which the highest reached over 1000 times higher than the median value. Two of the highest LnoMLV1 amounts were found in the two southern population male heads, $48 \%$ and $23 \%$ of all reads were coding for LnoMLV1. The highest virus read amounts in female lanterns coding for LnoMLV1 were $2 \%$ and $1.4 \%$ of all reads. There were no differences in the total viral load between the Hanko and Konnevesi populations $(t=0.08, p$-value $=0.94)$.

Glow-worms, irrespective of their gender or population, had seven different virus types, on average. A minimum of two and at the most nine virus types were observed (Fig. 2c). We studied whether the viruses affected each other's infection by pairwise correlations (Fig. 2d) and found two statistically significant interactions, read counts of LnoIV1 and TyLV1 correlated positively (Spearman's correlation coefficient $=0.6$, Holm's method adjusted $p$-value $=0.036$ ) and existence of the two partiti-like viruses correlated positively in the individuals (correlation coefficient $=0.8$, adjusted $p$-value $<0.0001)$.

\section{Glow-worm virus loads in different body sections}

We studied the virus loads by qPCR of glow-worm samples collected in 2018. Four female samples from Äänekoski and five female samples from Tvärminne were separated into head (the first segment, H), body (B), and eggs (E). The females were most probably unmated since they were still glowing when they were collected. Egg samples were scraped from body cavity and may have contained other tissues such as fat [29].

Additionally, three laboratory-reared larvae from southern Finland (Hanko) and three from southern England (Princes Risborough) were divided into head $(\mathrm{H})$ and body
(B) sections. Twelve isolated and unfed 2-week-old larvae from a single southern Finnish mother were split into two groups with six larvae in each $(2 \mathrm{wL} 1$ and $2 \mathrm{wL} 2)$ to yield enough RNA for experiment. All the viruses characterized from the 2017 samples, except LnoMLV1, were found from the 2018 female samples and their eggs (Fig. 3a), indicating that the viruses may be vertically and maternally transmitted. In further support of vertical transmission, we found LnoIV1, LnoIV2, LnoPLV1, LnoTLV1, and LnoERV1 from the unfed larval samples. Furthermore, all the viruses except LnoPLV1 and LnoMLV1 were also in the laboratoryreared larvae. Similar to the RNA-seq data, the prevalence of LnoRLV1 (67\%), LnoFV1 (73\%), LnoIV1 (100\%), LnoIV2 (100\%), and LnoERV1 (100\%) were high. Yet the prevalence of LnoPLV2, which was $24 \%$ in the 2017 data and was found to be $100 \%$ in the 2018 data. Further differences in LnoBLV1virus prevalence between the sample cohorts were $48 \%$ in the 2017 samples and 7\% in 2018 samples, and for LnoCLV1, the prevalence was 3\% in 2017 samples and $50 \%$ in 2018 samples.

In females, there was no significant difference in the distribution of viruses between head and body $(N=55$, $t=-1.12, p$-value $=0.27)$. However, the egg tissue had significantly lesser viruses than those in heads $(t=-3.94$, $p$-value $=0.00014)$ or bodies $(t=-2.695, p$-value $=0.0081$, Fig. 3b). In larvae, the heads had a significantly higher percentage of viruses than those in the bodies $(N=36, t=4.45$ $p$-value $=0.00003$, Fig. 3c).

There were no differences between populations in the virus load (mean + SE: Tvärminne 12,876 + 4581 and Äänekoski $9132.80+4874, \mathrm{t}=0.55$, $\mathrm{p}$-value $=0.60$ ). We excluded FN3 sample (Fig. 3a) from the analyses, as it had very high virus load.

\section{Discussion}

We identified 11 novel common glow-worm RNA viruses. In insects, viruses transmit horizontally through feeding, mating, or a vector [30]. Vertical virus transmission may occur through genome integration, such as for retroviruses or wasp polydnaviruses [31], or infection of eggs and sperm. Strict vertical transmission by infection of eggs or sperm is documented only for Drosophila sigmavirus [32]. Several insect viruses studied in bees and mosquitoes can transmit both horizontally and vertically [33, 34]. Vertical transmission has been hypothesized to be associated with low virulence and latent infection while under certain conditions, such as during host stress or presence of secondary hosts, virus activation enables horizontal transmission [33, 34]. Since glow-worms are in contact with each other only at birth, when foraging during larval stage, and during mating, within 
population transmission of viruses would be inefficient without vertical transmission.

However, horizontal transmission to and from mollusc is possible. Larvae had most of the viruses in their head segment, which may indicate possibility of horizontal transmission as the larvae are predators and salivary glands are known sites to carry viruses [35]. Adults do not feed and have no mouthparts and, consistently, had no significant differences in virus loads between head and body. Glow-worm adults and larvae are unlikely to be eaten by other insects as larvae and probably also adults are distasteful [1,3] and thus this kind of virus transmission pathway is not expected.

Most of the identified viruses were found from the glowworms collected both in 2017 and in 2018 suggesting that they form stable infections. As we found the same RNA virus sequences from the four spatially separate Finnish populations, we suspect that these viruses are a natural set of viruses infecting glow-worms and not an indication of a pathogenic state. However, LnoTyLVI is an exception. We could not find LnoMLV1 from the 2018 samples, and LnoMLV1 loads were extremely high in some of the 2017 samples: in the two male heads their amounts reached up to $48 \%$ and $23 \%$ of all the sequenced RNA reads. In comparison to negative- and double-stranded viruses, RNA levels of positive-strand RNA viruses, such as LnoMLV1, varied most between the glow-worm individuals. Similar phenomenon has also been seen in Argentine ant viruses [36]. However, such massive LnoMLV1 levels as found in the two males are clearly a result of pathogenic virus activation and might explain why we did not detect LnoMLV1 the next year. Viruses can be very reactive in a new host but then disappear suddenly if they fail to adjust and transmit [37].

Interestingly, we found five similar viruses from RNAsequencing data of another glowing insect: the common eastern firefly (Photinus pyralis). The common glow-worm and the eastern firefly are from the same Lampyridae family, which may explain why they share similar viruses. Yet, they do not occur in the same continent: eastern firefly is found in North America and common glow-worm only in Eurasia [4]. However, we did not find from our data the two orthomyxolike viruses, which were identified from the common eastern firefly and shown to transmit vertically [8].

As the light emitting ability of glow-worms is a major fitness factor, it will be interesting to study whether viruses affect the bioluminescence in larvae or females. According to our study, a whole range or viruses reside at lantern tissue so the light-regulating interaction could be possible.

Acknowledgements Open access funding provided by University of Oulu including Oulu University Hospital. This research was funded by the Academy of Finland Grants (No. 260147 to LV and No. 294664 to $\mathrm{AK}$ and $\mathrm{AMB}$ ) and Kone Foundation to JJ. The funders had no role in study design, data collection and interpretation, or the decision to submit the work for publication. Authors have no conflicting interests to declare relevant to this study.

Author contributions LV and JJ conceived of and designed the study; $\mathrm{LV}, \mathrm{AMB}, \mathrm{SS}$, and JJ performed the research; LV, AK, and JJ analyzed the data; and $\mathrm{JJ}$ wrote the paper.

Data availability The datasets generated and analyzed during this study are available with the corresponding author, on reasonable request.

\section{Compliance with ethical standards}

Conflict of interest The authors declare that they have no conflict of interest.

Ethical approval All applicable international, national, and/or institutional guidelines for the care and use of animals were followed.

Open Access This article is licensed under a Creative Commons Attribution 4.0 International License, which permits use, sharing, adaptation, distribution and reproduction in any medium or format, as long as you give appropriate credit to the original author(s) and the source, provide a link to the Creative Commons licence, and indicate if changes were made. The images or other third party material in this article are included in the article's Creative Commons licence, unless indicated otherwise in a credit line to the material. If material is not included in the article's Creative Commons licence and your intended use is not permitted by statutory regulation or exceeds the permitted use, you will need to obtain permission directly from the copyright holder. To view a copy of this licence, visit http://creativecommons.org/licenses/by/4.0/.

\section{References}

1. Underwood TJ, Tallamy DW, Pesek JD (1997) Bioluminescence in firefly larvae: a test of the aposematic display hypothesis (Coleoptera: Lampyridae). J Insect Behav 10:365-370. https:// doi.org/10.1007/BF02765604

2. Tyler J, McKinnon W, Lord GA, Hilton PJ (2008) A defensive steroidal pyrone in the Glow-worm Lampyris noctiluca $\mathrm{L}$. (Coleoptera: Lampyridae). Physiol Entomol 33:167-170. https ://doi.org/10.1111/j.1365-3032.2007.00610.x

3. De Cock R, Matthysen E (1999) Aposematism and bioluminescence: Experimental evidence from glow-worm larvae (Coleoptera: Lampyridae). Evol Ecol 13:619-639. https://doi. org/10.1023/A:1011090017949

4. Tyler J (2002) The glow-worm. Lakeside Printing Ltd, Kent, UK

5. Grassé P-P (1945) Traité de zoologie, anatomie, systématique, biologie. Masson et Cie.

6. Álvarez Guzmán RJ, De Cock R (2011) The biology and distribution of glow-worms (Coleoptera: Lampyridae ) in Spain. Lampyrid 1:22-31

7. Horne J, Horne A (2017) Larval development rates in the glowworm Lampyris noctiluca (L.). Lampyrid 4:55-58

8. Fallon TR, Lower SE, Chang C-H et al (2018) Firefly genomes illuminate parallel origins of bioluminescence in beetles. Elife 7:e36495 
9. Grabherr MG, Haas BJ, Yassour M, Levin JZ, Thompson DA, Amit I, Adiconis X, Fan L, Raychowdhury R, Zeng Q, Chen Z, Mauceli E, Hacohen N, Gnirke A, Rhind N, Palma di F, Birren BW, Nusbaum C, Friedman N, Regev A (2013) Trinity: reconstructing a full-length transcriptome without a genome from RNASeq data. Nat Biotechnol 29:644-652. https://doi.org/10.1038/ nbt.1883.Trinity

10. Huang X, Madan A (1999) CAP3: A DNA sequence assembly program. Genome Res 9:868-877. https://doi.org/10.1101/ gr.9.9.868

11. Camacho C, Coulouris G, Avagyan V et al (2009) BLAST+: architecture and applications. BMC Bioinformatics 10:421. https ://doi.org/10.1186/1471-2105-10-421

12. Dierckxsens N, Mardulyn P, Smits G (2016) NOVOPlasty: De novo assembly of organelle genomes from whole genome data. Nucleic Acids Res 45:e18. https://doi.org/10.1093/nar/gkw955

13. Thorvaldsdóttir H, Robinson JT, Mesirov JP (2013) Integrative genomics viewer (IGV): high-performance genomics data visualization and exploration. Brief Bioinform 14:178-192. https:// doi.org/10.1093/bib/bbs017

14. Li H, Durbin R (2009) Fast and accurate short read alignment with burrows-wheeler transform. Bioinformatics 25:1754-1760. https ://doi.org/10.1093/bioinformatics/btp324

15. Zimmermann L, Stephens A, Nam SZ et al (2018) A completely reimplemented MPI bioinformatics toolkit with a New HHpred Server at its Core. J Mol Biol 430:2237-2243. https://doi. org/10.1016/j.jmb.2017.12.007

16. Shi M, Lin X-D, Tian J-H et al (2016) Redefining the invertebrate RNA virosphere. Nature 540:539-543

17. Katoh K, Standley DM (2013) MAFFT multiple sequence alignment software version 7: improvements in performance and usability. Mol Biol Evol 30:772-780. https://doi.org/10.1093/molbe $\mathrm{v} / \mathrm{mst} 010$

18. Capella-Gutiérrez S, Silla-Martínez JM, Gabaldón T (2009) trimAl: a tool for automated alignment trimming in large-scale phylogenetic analyses. Bioinformatics 25:1972-1973. https://doi. org/10.1093/bioinformatics/btp348

19. Darriba D, Taboada G, Doallo R, Posada D (2011) ProtTest 3: fast selection of best-fit models of protein evolution. Bioinformatics 27:1164-1165

20. Guindon S, Dufayard JF, Lefort V et al (2010) New algorithms and methods to estimate maximum-likelihood phylogenies: assessing the performance of PhyML 3.0. Syst Biol 59:307-321. https://doi. org/10.1093/sysbio/syq010

21. Letunic I, Bork P (2019) Interactive Tree Of Life (iTOL) v4: recent updates and new developments. Nucleic Acids Res 47:W256-W259. https://doi.org/10.1093/nar/gkz239

22. Webster CL, Longdon B, Lewis SH, Obbard DJ (2016) Twentyfive new viruses associated with the drosophilidae (Diptera). Evol Bioinform 12:13-25. https://doi.org/10.4137/EBO.S39454

23. $\mathrm{Ng} \mathrm{W}$, Soto-Acosta R, Bradrick S et al (2017) The 5' and $3^{\prime}$ untranslated regions of the flaviviral genome. Viruses 9:137. https ://doi.org/10.3390/v9060137
24. Iwanaga $M$, Hitotsuyama $T$, Katsuma $S$ et al (2012) Infection study of Bombyx mori macula-like virus (BmMLV) using a BmMLVnegative cell line and an infectious cDNA clone. J Virol Methods 179:316-324. https://doi.org/10.1016/j.jviromet.2011.11.016

25. de Miranda JR, Scott Cornman R, Evans JD et al (2015) Genome characterization, prevalence and distribution of a macula-like virus from Apis mellifera and Varroa destructor. Viruses 7:35863602. https://doi.org/10.3390/v7072789

26. Katsuma $\mathrm{S}$, Tanaka $\mathrm{S}$, Omuro $\mathrm{N}$ et al (2005) Novel macula-like virus identified in Bombyx mori cultured cells. J Virol 79:55775584. https://doi.org/10.1128/JVI.79.9.5577-5584.2005

27. Wang L, Lv X, Zhai Y et al (2012) Genomic characterization of a novel virus of the family Tymoviridae isolated from mosquitoes. PLoS ONE 7:e39845. https://doi.org/10.1371/journal.pone.00398 45

28. Li CX, Shi M, Tian JH et al (2015) Unprecedented genomic diversity of RNA viruses in arthropods reveals the ancestry of negativesense RNA viruses. Elife 4:e05378. https://doi.org/10.7554/eLife .05378

29. Maas U, Sehn E, Harris JR, Dorn A (2001) Ergastoplasmic paracrystalline inclusion bodies in the adipose gonadal envelope and fat body of the glow worm, Lampyris noctiluca (Insecta, Coleoptera). Micron 32:129-140. https://doi.org/10.1016/S0968 $-4328(00) 00002-0$

30. Cory JS (2015) Insect virus transmission: different routes to persistence. Curr. Opin. Insect Sci. 8:130-135

31. Drezen JM, Chevignon G, Louis F, Huguet E (2014) Origin and evolution of symbiotic viruses associated with parasitoid wasps. Curr Opin Insect Sci 6:35-43

32. Longdon B, Jiggins FM (2012) Vertically transmitted viral endosymbionts of insects: do sigma viruses walk alone? Proc R Soc B Biol Sci 279:3889-3898

33. Tantillo G, Bottaro M, Di Pinto A et al (2015) Virus infections of honeybees Apis mellifera. Ital J Food Saf 4:5364. https://doi. org/10.4081/ijfs.2015.5364

34. Lequime S, Paul RE, Lambrechts L (2016) Determinants of arbovirus vertical transmission in mosquitoes. PLoS Pathog 12:e1005548. https://doi.org/10.1371/journal.ppat.1005548

35. Mellor PS (2000) Replication of arboviruses in insect vectors. J Comp Pathol 123:231-247

36. Viljakainen L, Holmberg I, Abril S, Jurvansuu J (2018) Viruses of invasive argentine ants from the European main supercolony: characterization, interactions and evolution. J Gen Virol 99:1129 1140. https://doi.org/10.1099/jgv.0.001104

37. Woolhouse MEJ, Haydon DT, Antia R (2005) Emerging pathogens: the epidemiology of species jumps. Trends Ecol Evol $20: 238-244$

Publisher's Note Springer Nature remains neutral with regard to jurisdictional claims in published maps and institutional affiliations. 